\title{
Decline in Fish Stock and Livelihood of Small-Scale Fisheries in Shores of Lake Victoria, Tanzania
}

\author{
Yohana James Mgale, Nicholaus Edward Nikusekela \\ Institute of Rural Development Planning (IRDP), Department of Rural Development and Regional Planning, Dodoma, Tanzania
}

\section{Email address:}

ymgale@irdp.ac.tz (Y.J. Mgale),nkamson83@gmail.com (N. E. Nikusekela)

\section{To cite this article:}

Yohana James Mgale, Nicholaus Edward Nikusekela. Decline in Fish Stock and Livelihood of Small-Scale Fisheries in Shores of Lake

Victoria, Tanzania. International Journal of Applied Agricultural Sciences. Vol. 3, No. 4, 2017, pp. 87-91. doi: 10.11648/j.ijaas.20170304.11

Received: February 28, 2017; Accepted: May 26, 2017; Published: June 30, 2017

\begin{abstract}
The objective of this study was to analyse the decline of fish stock and its effects to the livelihood of small scale fisheries. The study was conducted at Ilemela District in Mwanza region, Tanzania. Data were collected through interview and focus group discussion with the sample size of 84 respondents plus 4 key informants. The SPSS and STATA software were used in analyzing the collected data and information. This study shows that there are significant changes in amounts of fish catches per day by households in all seasons [before and after decline in fish stock in shores of Lake Victoria in Tanzania]. Using descriptive statistics, the catches in low season before decline in fish stock has a mean score of 83.75 as compared to a mean score of 18.33 after decline in fish stock and also catches in high season before decline has a mean score of 158.21 as compared to a mean score of 55.833 after decline this impacted the household on the expenses that depend on the income obtained from fishing activities i.e. purchasing food, clothes, paying hospital bills and school fees. However, illegal fishing and fishing methods i.e. higher temperature caused by climate change, lack of alternative sources of income, population growth and unemployment are major constraints to full exploitation of fishing [production potential] and jeopardizes efforts to improving productivity on the sector. In this regard, government intervention is needed to attract investor or donor in the fish and fishing sector who will provide training to small scale fisheries and ensuring awareness towards fisheries resource in the shores of Lake Victoria and this will reduce the decline of fish stock. In addition, the development partners [provide technical and finances] and government [provide institutional framework, technical and financial] should play great role in protecting fishing in shores of Lake Victoria in Tanzania to ensure that, bylaws are formulated to enforce adoption of improved fishing methods and reduce unemployment rate to youth by investing in high labor absorption sectors i.e. labor intensive industries which will contribute to nation GDP.
\end{abstract}

Keywords: Decline, Fish Stock, Livelihood, Small Scale, Fisheries, Lake Victoria

\section{Introduction}

\subsection{Overview}

Fishing has been a major source of food for humanity and a provider of employment and economic benefits to households in the world for a long period of time. 90 percent of 38 million people recorded globally as fishers are classified as small scale, and an additional 100 million people are estimated to be involved in the small-scale post-harvest sector [1]. Until the late $19^{\text {th }}$ century, the fish resources of the world were thought to be essentially inexhaustible, even by the most prominent biologists [2]. As the fishing industry expanded and technology made larger catches possible and more areas of the lake exploitable, the received wisdom that fisheries were inexhaustible soon became discredited. FAO estimates that 25 percent of the world's fish stocks are currently being fished at an unsustainable level [3], thus risking collapse and fish are a common pool resource, meaning that it is difficult to exclude users and that exploitation by one user reduces the resource availability for others [4]. Fisheries sector in Tanzania is among the important economic sub-sectors of the economy. The sector provides substantial employment, income, livelihood, foreign earnings and revenue to the country. They contribute about half of the global catch, supplying food for local, national, and global markets. They also account for approximately 90 percent of fishing employment along the global supply chain [5]. According to the Ministry of 
Livestock and Fisheries Development report, [2] the industry employs more than 4,000,000 people engaged in fisheries and fisheries related activities while more than 400,000 fisheries operators are directly employed in the sector.

\subsection{Justification of the Study}

Lake Victoria contributes significantly to the economic growth of the East African countries [6] [7]. For many Years Lake zone regions including Mwanza were blessed with a variety of resources which were tapped especially in areas of fishing, but today the situation had worsened as some of the fish species in the Lake Victoria were illegally exploited. Ntiba observed that fisheries in Lake Victoria are free and unrestricted; anyone can make or buy a vessel and start fishing [8]. The lake fisheries is also characterized as a regulated open access fishery, which means that participants are free to enter, subject to regulations like gear restrictions, area closer and seasonal restrictions. Hence, the ability of fisheries institutions to create a positive incentive structure is undermined by the complex nature of fishing and the fact that enforcement often is difficult to exercise [8].

According to Lake Victoria environmental management programme shows that Nile perch stock dropped from 750,000 tones to 337,000 tones and tilapia dropped from 27,061 tones to 24,811 tones in the year 2005 to 2008 [6]. So now Lake zone regions particularly Mwanza region facing a huge fish decline due to illegal fishing, over fishing and climate change which threatening the sustainability of some fish species in the Lake Victoria. The government of Tanzania has established some efforts such as policy, laws and regulations to combat issues of illegal and unsustainable fishing. Fishermen often question the results of stock assessment surveys and maintain that there is more fish in the lake than biologists can count. They often express their opinion that the fish in the lake can never be finished and wonder why the government is restricting the exploitation of a resource freely given by God the almighty. Of course, the problem seems to have been enhanced by difficulty to harmonize different political laws and surveillance logistics governing the giant water resource [8].

Despite of these efforts to rescue fish stocks in Lake Victoria, yet, fish stock is declining at an alarming rate, which is characterized by increase of price per kilogram as a result of fish shortage. As a result, the decline has negative effects to the livelihood of small scale fisheries. This paper therefore analyzed the decline of fish stock and its effects to the livelihoods of small scale fisheries in shores of Lake Victoria, Tanzania.

\section{Material and Methods}

\subsection{Study Area}

The study was conducted in Ilemela district in Mwanza region. Ilemela district is one of the seven districts of Mwanza region of Tanzania. It is bordered to the north and west by Lake Victoria, to the east by Magu district, and to the south by
Nyamagana district. Part of the region's capital, the town of Mwanza is within Ilemela District. As of 2012 census, the population of the Ilemela District was 343,001 [9] [10].

\subsection{Research Design}

This research used a descriptive cross-sectional research design. This design was selected because it enables the researcher to compare many different variables at the same time, for example age, gender, marital status, income levels and education level [11]. The study involves the arrangement of conditions for collection and analysis of data in a manner that aims to combine relevance with the research purpose.

\subsection{Sample and Sampling Procedure}

Probability and non-probability sampling was employed. Simple random sampling (probability sampling) was used to obtain respondents from the three selected streets and purposive sampling (non-probability) was used to get information from key informants such as fishery officers. Using formula developed by Yamane [12], $\left[n=N /(1+N(e))^{2}\right.$ where $\mathrm{n}$ is sample size, $\mathrm{N}$ is the population size and $\mathrm{e}$ is the level of precision]. The sample size used for analysis and conclusion was 84 households and 4 key informants.

\subsection{Data Collection Methods and Tools}

Primary and secondary data were collected using various methods including interview, observation and documentary review. Kothari and Paul mentioned that the use of different methods enabled triangulation of different data collected to ensure accuracy and better quality [13] [14]. The interview method of collecting data involves presentation of oral-verbal stimuli and reply in terms of oral-verbal responses from respondents (households).

\subsection{Data Analysis}

Both descriptive and inferential analyses were used. Descriptive analysis used cross tabulation to present frequencies, percentage, mean and standard deviation. Inferential analysis used logistic regression to analyze the relationship between variables of concern on fish stock decline. Inferential statistics, i.e. F-test, chi-square and correlation coefficient $\left(\mathrm{R}^{2}\right)$ were presented.

\section{Results and Discussion}

\subsection{Characteristics of Respondents}

Socio-demographic characteristics of respondents are presented in Table 1. Distribution of respondents varied among age groups and sex between the three fishing camps. The majority of small scale fisheries $(64.3 \%)$ were aged 35 64 and fishing was a predominantly male activity $(92.9 \%$ male; $7.1 \%$ female). Married individuals $(82.1 \%)$ constituted the highest group engaged in fishing activities compared to other categories. Middle family size (4-6 members) with $65.5 \%$ responses was a characteristic observed in small scale 
fisheries. This scenario could be attributed to increased labor force in large families. The $\chi^{2}$ values indicate that, fishing was independent of age, sex, marital status, education and household size $(P>0.05)$ which is probably due to the fact that majority of the respondents had similar sociodemographic background.

Table 1. Socio-demographic characteristics of respondents.

\begin{tabular}{|c|c|c|c|c|c|c|}
\hline \multirow[b]{2}{*}{ Variable } & \multirow{2}{*}{ Description } & \multicolumn{3}{|c|}{ Fishing Camps } & \multirow[b]{2}{*}{ Average } & \multirow{2}{*}{$\chi^{2}$ Value } \\
\hline & & Kigoto & Ibanda Busisi & Ibanda Ziwani & & \\
\hline \multirow{3}{*}{ Age } & $<35$ & 8.8 & 14.3 & 9.1 & 10.7 & \multirow{3}{*}{3.205} \\
\hline & $35-64$ & 73.5 & 60.7 & 54.5 & 64.3 & \\
\hline & $>65$ & 17.6 & 25.0 & 36.4 & 25.0 & \\
\hline \multirow{3}{*}{ Sex } & Male & 97.1 & 92.9 & 86.4 & 92.9 & \multirow{2}{*}{2.304} \\
\hline & Female & 2.9 & 7.1 & 13.6 & 7.1 & \\
\hline & Primary & 61.8 & 71.4 & 59.1 & 64.3 & \\
\hline \multirow[t]{2}{*}{ Education } & Secondary & 32.4 & 25.0 & 22.7 & 27.4 & \multirow[t]{2}{*}{4.455} \\
\hline & Informal & 5.9 & 3.6 & 18.2 & 8.3 & \\
\hline \multirow{2}{*}{ Marital status } & Single & 11.8 & 28.6 & 13.6 & 17.9 & \multirow{2}{*}{3.319} \\
\hline & Married & 88.2 & 71.4 & 86.4 & 82.1 & \\
\hline \multirow{3}{*}{ Household size } & $1-3$ & 2.9 & 3.6 & 4.5 & 3.6 & \multirow{3}{*}{1.725} \\
\hline & $4-6$ & 67.6 & 71.4 & 54.5 & 65.5 & \\
\hline & $>6$ & 29.4 & 25.0 & 40.9 & 31.0 & \\
\hline
\end{tabular}

\subsection{Contribution of Small Scale Fisheries to Household Income}

To determine contribution of fishing sub-sector to household income, fishermen were asked to indicate their annual income from fisheries and other sources. Income from fishing was derived by multiplying the amount of catches in $\mathrm{kg}$ per day with its market price [5000TZS per kg: (1USD $\approx$ TZS2150)] and then descriptive statistics were calculated. The mean income per year per person was 2,084,833TZS which is equivalent to 5,711.87TZS and its standard deviation was 531180.8. This implies that households in this study area are better off and there is no food insecurity because the overall mean income is above the poverty line of 1,594 TZS [15] [16].

Table 2. Catches of fish before and after decline in fish stock.

\begin{tabular}{llll}
\hline \multirow{2}{*}{ Variable } & Before DFS (n=84) & & After DFS (n=84) \\
\cline { 2 - 4 } & Mean & Std. Dev. & Mean \\
\hline Catches in $\downarrow$ season (kg per day) & 83.75 & 16.03601 & 18.33333 \\
Catches in $\uparrow$ season (kg per day) & 158.2143 & 36.96826 & 7.278179 \\
\hline
\end{tabular}

DFS- decline in fish stock

Results in Table 2 shows that there is a significant change in amount of fish catches per day by households in all seasons before and after decline in fish stock in shores of Lake Victoria in Tanzania. Using descriptive statistics, the catches in low season before decline in fish stock has a mean score of 83.75 as compared to a mean score of 18.33 after decline in fish stock and also catches in high season before decline has a mean score of 158.21 as compared to a mean score of 55.833 after decline. The standard deviation (SD) in low season was 16.03 and 7.28 for before and after decline respectively and in high season were 36.97 and 8.208 for before and after decline of fish stock respectively. This revealed that the livelihood of small scale fisheries household has declined since the income received depends on the quantity of fish catches.

\subsection{Household Consumption Expenditure}

To determine expenditure of income earned in fishing sub-sector, fishermen were asked to indicate their daily expenses for food, clothes, shelter and other uses. Annual expenses were derived by multiplying the expenses per day by number of days per year (365 days) and then descriptive statistics were calculated. Results in Table 3 shows that income obtained from fishing activities were used in purchasing food, clothes, paying hospital bills and school fees. Their expenditure was as follows; food ranked number one having mean expenses of $1,729,184 \mathrm{TZS}$, followed by clothes $(196,404 \mathrm{TZS})$ paying school fees $(117,093 \mathrm{TZS})$ and lastly the hospital expenses with mean expenses of 91,380.95TZS. This therefore revealed that small scale fisheries contribute much to the livelihood of their households and decline of fish stock endangered their welfare because there will be inadequate income to fulfill the welfare needs of the community living in shores of Lake Victoria in Tanzania.

Table 3. Income spending in fishing households.

\begin{tabular}{lllll}
\hline Variables (years) & Obs & Mean & Std. Dev. & Min \\
\hline Income spent for food & 84 & $1,729,184$ & $505,258.1$ & $1,000,000$ \\
Income spent for hospital & 84 & $91,380.95$ & $39,443.08$ & 40,000 \\
Income spent for school fees & 43 & 117,093 & $81,687.8$ & $7,240,000$ \\
Income spent for clothes & 84 & $196,404.8$ & $51,646.18$ & 180,000 \\
\hline
\end{tabular}




\subsection{Factors for the Decline in Fish Stock}

Correlation coefficient $\left(\mathrm{R}^{2}\right)$ and F-test $(\mathrm{F})$ statistics were determined using a multiple regression analysis to find out the variation in decline of fish stock in shores of Lake Victoria in Tanzania. The factors for decline of fish stock i.e. climate, fishing methods, reliable source of income, population growth and unemployment was determined if they could explain the variation in total fish stock in the study area. The dependent variable, decline in fish stock, was modeled against the independent variables; climate i.e. dry season, winter, temperature; fishing methods i.e. beach seine, mesh size, fishing nets, hooks, water splash, monofilament net, poison; introduction of Nile perch; population growth; reliable source of income and unemployment. The results are presented in Table 4.

Results shows the correlation coefficient $\left(\mathrm{R}^{2}\right)$ value of about 0.8488 which means that about 84.88 percent of the variation in decline in fish stock is explained by fishing methods, climate, population growth, income, and unemployment. The value of $\mathrm{R}^{2}$ shows there is a strong correlation between decline in fish stock and factors for decline. The distribution of household members involves in fishing as economic activities have an $F$ value $[F(14,69)=34.29]$ with $P r o b>F=0.000$ which means that all factors for decline in fish in the study area varies between wards were the households are residing because the $\mathrm{F}$ value is significant at confidence interval of $95 \%$. The values obtained are below the critical value $(\mathrm{P}<0.05)$.

Table 4. Multiple regression on factors for the decline of fish stock.

\begin{tabular}{|c|c|c|c|c|c|c|}
\hline DFS & Coef. & Std. & Err & $\mathbf{t}$ & $\mathbf{P}>|\mathbf{t}|$ & [95\% Conf. Interval] \\
\hline Smesh & 0.05483 & 0.0397436 & 1.38 & 0.172 & $-0.0244563 * *$ & 0.1341162 \\
\hline Beachsein & 0.1347021 & 0.0450291 & 2.99 & 0.004 & $0.0448716 * *$ & 0.2245327 \\
\hline Snet & 0.0131848 & 0.0307009 & 0.43 & 0.669 & $-0.0480617 * *$ & 0.0744314 \\
\hline Shook & 0.0162306 & 0.0349932 & 0.46 & 0.644 & -0.0535789 & 0.0860401 \\
\hline Poison & 0.0515184 & 0.031195 & 1.65 & 0.103 & $-0.010714^{* *}$ & 0.1137508 \\
\hline Wsplash & 0.0728803 & 0.0331203 & 2.20 & 0.031 & $0.0068071 *$ & 0.1389535 \\
\hline Mononet & 0.004423 & 0.0328373 & 0.13 & 0.893 & -0.0610856 & 0.0699316 \\
\hline Swinter & 0.044687 & 0.0432993 & 1.03 & 0.306 & $-0.0416927 * *$ & 0.1310667 \\
\hline Htemp & 0.0602482 & 0.0384363 & 1.57 & 0.122 & $-0.0164301 * *$ & 0.1369266 \\
\hline Enperch & 0.2313737 & 0.0699171 & 3.31 & 0.001 & 0.0918929 & 0.3708546 \\
\hline Hdemand & 0.0585697 & 0.0447238 & 1.31 & 0.195 & $-0.0306518 * *$ & 0.1477912 \\
\hline Infishing & -0.0324792 & 0.0306298 & -1.06 & 0.293 & -0.093584 & 0.0286256 \\
\hline Unp & 0.304139 & 0.0626548 & 4.85 & 0.000 & 0.1791461 & 0.4291319 \\
\hline Constant & 0.0689355 & 0.0405474 & 1.70 & 0.094 & $-0.0119544 * *$ & 0.1498255 \\
\hline
\end{tabular}

Prob > F $=0.0000 ; \mathrm{R}^{2}=0.8743 ;$ Adj $\mathrm{R}^{2}=0.8488$

$*$ and $* *$ statistically significant at $1 \%$ and $5 \%$ respectively

Further analysis shows that, only five variables used in assessing decline in fish stock (DFS) was insignificant at $\mathrm{P}<0.05$ which includes fishing methods (monofilament nets (Mononet) and small hooks (Shook)), unemployment levels (Unp), introduction of Nile perch (Enperch) in the lake and increase in number of fishermen (Infishing) but other factors [climate (i.e. dry season (Dseason), strong winter (Swinter), increase in temperature (Htemp)); fishing methods (i.e. beach seine (Beachsein), mesh size (Smesh) smaller than 6 inches, fishing nets (Snet), hooks, water splash (Wsplash), monofilament net, poison); population growth (Hdemand) causing high demand for fishing activities as the only income source] were significant at $\mathrm{P}<0.05$ and positive related with dependent variable (decline in fish stock) meaning that increase in population growth and overuse of prohibited fishing methods cause more decrease in fishing stock.

\section{Conclusions and Recommendations}

This study has shown that small scale fisheries are significant drivers for growth and a major source of income for the small-scale fisheries in shores of Lake Victoria in Tanzania. Indeed, this activity plays an important role in household food security and the overall welfare of small scale fisheries. However, illegal fishing and fishing methods i.e. higher temperature caused by climate change, lack of alternative sources of income, population growth and unemployment are major constraints to full exploitation of fishing [production potential] and jeopardizes efforts to improving productivity on the sector.

In this regard, government intervention is needed to attract investor or donor in the fish and fishing sector who will provide training to small scale fisheries and ensuring awareness towards fisheries resource in the shores of Lake Victoria and this will reduce the decline of fish stock. Also, development partners in collaboration with the government and fishing community should introduce fish farming in ponds which will encourage fishermen to adopt improved fish production and hence improve their household income. In addition, the development partners [provide technical and finances] and government [provide institutional framework, technical and financial] should play great role in protecting fishing in shores of Lake Victoria in Tanzania to ensure that, bylaws are formulated to enforce adoption of improved fishing methods and reduce unemployment rate to youth by investing in high labor absorption sectors i.e. labor intensive industries which will contribute to nation GDP. 


\section{References}

[1] C. Bene, "Small scale fisheries: Assessing their contribution to rural livelihoods in developing countries," FAO Fisheries Circular No. 1008., 2006.

[2] LVFRP, "Lake Victoria Fisheries Research Project:," Universities of the North of England Consortium for International Activities, 2001.

[3] Wandera, S. B., Nsinda, P. and Rabuor, C., "The potential of the Lake Victoria offshore dagaa (Rastrineobolaargentea) fishery," Lake Victoria Fisheries Organisation, Jinja, Uganda., 2006.

[4] Onyango, P. O., "Contribution of Lake Victoria fisheries to Tanzania's economic growth, poverty status and development," Lake Victoria Fisheries Organisation, Jinja, Uganda, 2007.

[5] Stevens, K., Frank, K. A. and Kramer, D. B., "Social Networks Influence Small-Scale Fishermen's Enforcement of Sea Tenure," PLoS ONE 10(3): e0121431.doi: 10.1371/ journal. pone.012143., 2015.

[6] LVFO, "Technical Report: Stock Assessment Regional Working Group," Lake Victoria Fisheries Organisation, 28 pp, Jinja, Uganda, 211.

[7] LVFO, " Regional status report on the Lake Victoria biennial frame surveys between 2000 and 2012," Lake Victoria Fisheries Organization, 2013.

[8] Ojuok, J. E., Njiru, M., Ntiba, M. J. and Mavuti, K. M., "The effect of overfishing on the life-history strategies of Nile tilapia, Oreochromisniloticus (L.) in the Nyanza Gulf of Lake Victoria, Kenya," Aquatic Ecosystem Health and Management, 2007.

[9] National Bureau of Statistics, "The 2012 population and housing census: Population distribution by administrative areas," National Bureau of Statistics., Dar es Salaam, 2013.

[10] National Bureau of Statistics, "Population and housing census 2012 Tanzania," National Bureau of Statistics, Dar Es Salaam, 2012.

[11] Casley, D. J. and Kumar, K., Project Monitoring and Evaluation in Agriculture, Baltimore and London: The Johns Hopkins University Press, 1988.

[12] T. Yamane, Statistics, an, Introductory Analysis 2rd Ed., New York: Harper and Canada, 1967.

[13] C. Kothari, Research Methodology: Methods and Techniques, New Delhi: New Age International (P) Ltd., 2nd Edition, 2004.

[14] Paul, F., "Taming Youth Unemployment in Africa," 2014. [Online]. Available: http:ghanaweb.com/ghanahomepage. [Accessed 10th March 2015].

[15] URT, "United Nations Educational, Scientific and Cultural Organization (UNESCO) Country Programming Document 2011-2015," UNESCO, 2015.

[16] W. Bank, "htttp://www1.worldbank.org/publicsetor/decentralization/diff erent.htm.," 2002. [Online].

[17] R. Chambers, Editorial introduction - Vulnerability: how the poor cope. IDS Bulletin 20(2), Brighton: Institute of Development Studies, University of Sussex, 1989.

[18] Lake Victoria Basin Commission (LVBC), A study on Aquatic Biodiversity in the Lake Victoria Basin, Kenya: ACTS Press, African centre for technology studies, 2011.

[19] F. Sobo, "Community Participation in Fisheries Management in Tanzania," IIFET, Dar Es Salaam, 2012.

[20] Cowx, I. G, Knaap, M. Van Der, Muhoozi, L. I. and Othina, A., "Improving fishery catch statistics for Lake Victoria," vol. 6, p. 299-310, 2003.

[21] Mkenda, A. F., Luvanda, E. G., Rutasitara, L. and Naho, A., "Poverty in Tanzania: Comparisons across Administrative Regions, An Interim Report. 21 pp.," Dar Es Salaam, 2004.

[22] Katikiro, R, Macusi, E and Deepananda, A. KHM, "Changes in Fisheries and Social Dynamics in Tanzania Coastal Fishing Communities," Western Indian Ocean J. Mar Sci., vol. 12, no. 2, pp. 95-110, 2013.

\section{Biography}

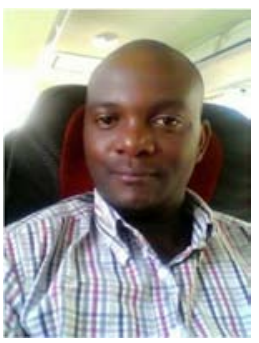

Mr. Nicholaus Edward Nikusekela has a Master Degree in Development Economics offered jointly by Wageningen University the Netherlands and Institute of Rural Development Planning (IRDP) in Tanzania; Bachelor Degree of Science (BSc.) in Agricultural Economics and Agribusiness of Sokoine University of Agriculture (SUA) in Tanzania. Mr. Nikusekela is also a Managing Director for N2CL Consulting. He has extensive experience of working in areas of training (capacity building), research, trade, planning \& investment, budgeting and Monitoring and evaluation (M\&E). Also has experience in project Designing\& Implementation using models i.e. PMMM and approaches i.e. LEAP, CDAB, CDAC, PLA, and O\&OD.

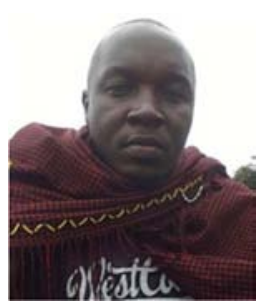

Mr. Yohana James Mgale, Assistant Lecturer in the Department of Rural Development and Regional Planning, Institute of Rural Development Planning DodomaTanzania. He holds a Master's of Science Degree in Economics together with Bachelor of Science in Agricultural Economics and Agribusiness. Apart from teaching, he has been responsible for conducting Market Research (value chain, socio economic studies), Baseline Survey, Preparing, Implementing, Monitoring and Evaluating Projects, Enterprise Management (mainly in agribusiness sector), Data Managements Community Mobilization, Group Formation and Management, Lobbying and Advocacy, Policy and Welfare Analysis. 